\title{
Mechanical Ventilation Basic Terms and Physiology
}

\author{
Behzad Saberi* \\ MD, Medical Research, Esfahan, Iran \\ *Corresponding author: Behzad Saberi, MD, Medical Research, Esfahan, Iran
}

\section{Terms and Physiology}

There are some terms related to mechanical ventilation which the healthcare professionals who deal with the patients who are placed on the ventilator for various reasons, should have knowledge about them.

Based on the selected mode of mechanical ventilation there are "Control "variables like volume or pressure-controlled ventilation modes. Mechanical ventilation's dependent variables are “ Conditional " variables. " Trigger " initiates the inspiration. As a matter of fact, one breath can be time, pressure or flow triggered. End of inspiration and beginning of exhalation determinant would be the "Cycle ". The mechanical ventilator can be time, volume and pressure cycled. Mechanical respiratory cycle's resistive forces are named " Airway resistance " which its normal range is equal to or lower than $5 \mathrm{cmH}_{2}$ O. [1-2]

Atelectasis causes surface area's gas exchange loss which is called " De-recruitment ". Increasing PEEP can minimize Derecruitment which is among the most common cause of gradual hypoxemia in the patients who are intubated. Reopening the lung's atelectatic or collapsed areas with pressure application and gas exchange surface area's restoration, is called " Recruitment ". Lungs elasticity or their ease to expand and stretch in response to volume or pressure changes is called "Lung compliance ". Highly compliant lungs can be seen in the Obstructive lung diseases and Lungs with a low compliance can be seen in Restrictive lung diseases as an example. The weight which should be used in ventilator settings determination is " Predicted body weight " or " PBW ". Height and sex are two factors which determine lung volumes and therefore they should be used in PBW determination. [3-4]

\section{References}

1. Weingart SD (2016) Managing Initial Mechanical Ventilation in the Emergency Department. Ann Emerg Med 68(5): 614-617.

2. Pham T, Brochard LJ, Slutsky AS (2017) Mechanical Ventilation: State of the Art. Mayo Clin Proc 92(9): 1382-1400.

3. Sutherasan Y, Vargas M, Pelosi P (2014) Protective mechanical ventilation in the non-injured lung: review and meta-analysis. Crit Care 18(2): 211.

4. Singer BD, Corbridge TC (2009) Basic invasive mechanical ventilation. South Med J 102(12): 1238-1245.

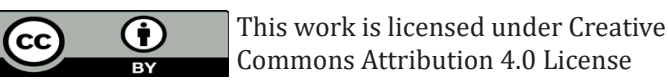

To Submit Your Article Click Here:

Submit Article

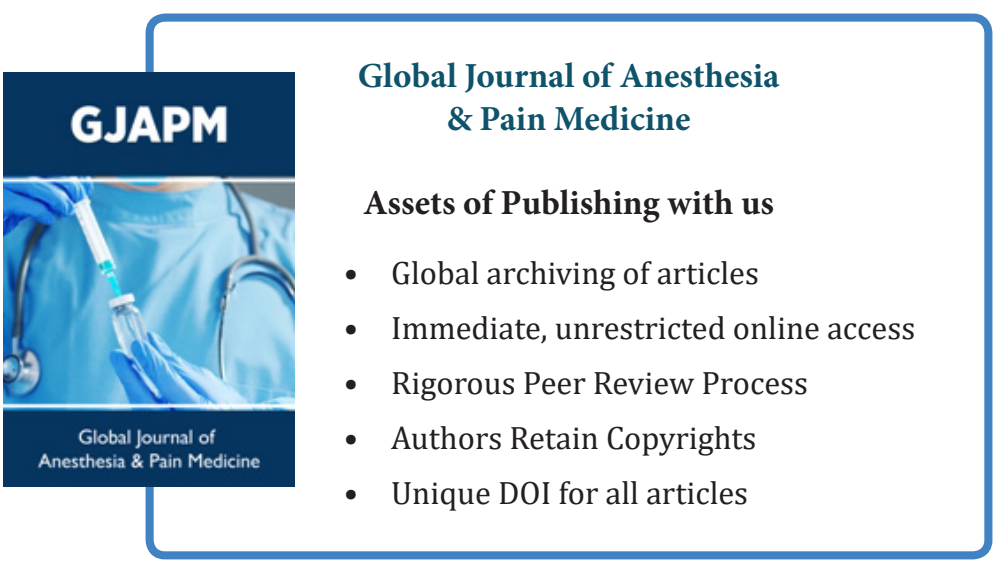

